\title{
Effects of alfalfa and organic fertilizer on benzo[a]pyrene dissipation in an aged contaminated soil
}

\author{
Dengqiang Fu • Ying Teng • Yongming Luo • Chen Tu • \\ Shixing Li $\cdot$ Zhengao Li $\cdot$ Peter Christie
}

Received: 17 May 2011 / Accepted: 14 November 2011 / Published online: 2 December 2011

(C) The Author(s) 2011. This article is published with open access at Springerlink.com

\begin{abstract}
Background A climate-controlled pot experiment was conducted to investigate the effects of planting alfalfa and applying organic fertilizer on the dissipation of benzo[a] pyrene from an aged contaminated agricultural soil.

Results Short-term planting of alfalfa inhibited the dissipation of benzo[a]pyrene from the soil by $8.9 \%$, and organic fertilizer enhanced benzo[a]pyrene removal from the soil by $11.6 \%$ compared with the unplanted and unfertilized treatments, respectively. No significant interaction was observed between alfalfa and organic fertilizer on benzo[a]pyrene dissipation. Sterilization completely inhibited the removal of benzo[a]pyrene from the soil indicating that its degradation by indigenous microorganisms may have been the main mechanism of dissipation. Furthermore, significant positive relationships were observed between benzo[a] pyrene removal and the contents of soil ammonium nitrogen, nitrate nitrogen, and total mineral nitrogen at the end of the experiment, suggesting that competition between plants and microorganisms for nitrogen may have inhibited benzo[a]pyrene dissipation in the rhizosphere of alfalfa and
\end{abstract}

Responsible editor: Zhihong $\mathrm{Xu}$

D. Fu $\cdot$ Y. Teng $\cdot$ Y. Luo $(\bowtie) \cdot$ C. Tu $\cdot \mathrm{S}$. Li $\cdot \mathrm{Z}$. Li

Key Laboratory of Soil Environment and Pollution Remediation, Institute of Soil Science, Chinese Academy of Sciences,

Nanjing 210008, China

e-mail: ymluo@issas.ac.cn

D. $\mathrm{Fu} \cdot \mathrm{Y}$. $\mathrm{Luo} \cdot \mathrm{S}$. Li

Graduate University of Chinese Academy of Sciences,

Beijing 100049, China

P. Christie

Agri-Environment Branch, Agri-Food and Biosciences Institute,

Newforge Lane,

Belfast BT9 5PX, UK the addition of organic fertilizer may facilitate microbial degradation of benzo[a]pyrene in the soil.

Keywords Alfalfa - Organic fertilizer Benzo[a]pyrene · Aged contaminated soil

\section{Introduction}

Polycyclic aromatic hydrocarbons (PAHs) are of particular concern due to their hydrophobic, recalcitrant, persistent, potentially carcinogenic, mutagenic, and teratogenic properties and their ubiquitous occurrence in the environment (Flowers et al. 2002; Samanta et al. 2002; Johnsen and Karlson 2007; Patrolecco et al. 2010; Wolz et al. 2011). Most of the PAHs in the environment are present in surface soils (Wild and Jones 1995; Wilcke 2007). Bioremediation is regarded as a promising strategy for restoring contaminated agricultural soils (Peng et al. 2008; Silva et al. 2009; Zhang et al. 2010). Numerous studies have shown that many plant species may promote PAH degradation in soils because plant root exudates, rich in organic acids and mineral nitrogen, may increase the indigenous soil microbial population including PAH-degrading microorganisms (Wetzel et al. 1997; Binet et al. 2000; Liste and Alexander 2000; Muratova et al. 2003; Cofield et al. 2007; Wei and Pan 2010; Teng et al. 2011). Other studies have also shown that some plants may inhibit the removal of PAHs from contaminated soil (Cofield et al. 2007; Smith et al. 2008). Competition for nutrients between plants and soil microorganisms may impede PAH removal in the rhizosphere. Alfalfa (Medicago sativa L.), the most widely grown perennial legume in the world, is a deep-rooted perennial species that may have strong potential for the remediation of a number of organic contaminants, such as polychlorinated 
biphenyls and PAHs (Chekol et al. 2004; Fan et al. 2008; Teng et al. 2011). Muratova et al. (2003) suggested that alfalfa root exudates are high in organic acids and mineral nitrogen and can promote the growth of soil microorganisms, including PAH degraders. Furthermore, Cheng et al. (2008) found that organic fertilizer application can enhance the biodegradation of PAHs in rhizoshpere soil. However, most of these studies have been conducted with experimentally (artificially) contaminated soils and have concentrated on low molecular weight PAHs such as phenanthrene and pyrene. However, little is known about the effects of alfalfa and organic fertilizer on high molecular weight PAHs such as benzo[a]pyrene dissipation in an aged contaminated soil. And the influence of nutrient in organic fertilizer, especially mineral $\mathrm{N}$, on the dissipation of benzo[a]pyrene is greatly concerned about.

Our recent study found that total concentrations of 16 US Environmental Protection Agency (USEPA) priority PAHs in some surface soils in the Yangtze River Delta region of east China were over $10.0 \mathrm{mg} \mathrm{kg}^{-1}$ dry soil and the benzo[a]pyrene content reached $1.0 \mathrm{mg} \mathrm{kg}^{-1}$. According to the Canadian Environmental Quality Guidelines released by the Canadian Council of Ministers of the Environment (CCME 2004), this soil would not be suitable for agricultural use because of its high concentration of PAHs. Remedial measures would be required to restore normal soil function.

The aim of the present study was to determine whether planting alfalfa and applying organic fertilizer would have significant effects on the dissipation of benzo[a]pyrene from a long-term contaminated agricultural soil. In addition, soil mineral nitrogen and $\mathrm{pH}$ were determined to investigate the relationships between soil properties and benzo[a]pyrene dissipation. It was hoped that the results would be useful in understanding the potential for remediating a real agricultural soil contaminated with benzo[a] pyrene.

\section{Materials and methods}

\subsection{Soil}

The soil studied was collected from the top $15 \mathrm{~cm}$ of a PAH-contaminated agricultural field in the Yangtze River Delta region of east China. The contaminated site was adjacent to a gas station which has resulted in PAH pollution over a 30-year period, and PAHs were the main contaminants in the soil according to our previous study (Teng et al. 2011). The soil type is classified as a Hortic Anthrosol according to the World Reference Base soil classification system. Stones and plant root residues in the sampled soil were discarded. The soil was then air-dried, sieved through a $2-\mathrm{mm}$ mesh, and stored at $4{ }^{\circ} \mathrm{C}$ in the dark prior to use. Physicochemical analysis according to the methods of Lu (1999) shows that the soil is a silt loam with an average organic matter content of $23.4 \mathrm{~g} \mathrm{~kg}^{-1}, 1.44 \mathrm{~g}$ $\mathrm{kg}^{-1}$ total nitrogen, $0.86 \mathrm{~g} \mathrm{~kg}^{-1}$ total phosphorus, $12.3 \mathrm{~g}$ $\mathrm{kg}^{-1}$ total potassium, $5.02 \mathrm{mg} \mathrm{kg}$-1 ammonium nitrogen, and $3.16 \mathrm{mg} \mathrm{kg}^{-1}$ nitrate nitrogen, soil pH 4.5 (1:2.5 soil/ water) determined using a $\mathrm{pH}$ meter. Total concentrations of 16 USEPA priority PAHs in the soil were $12.4 \mathrm{mg} \mathrm{kg}^{-1}$ dry soil, with three-ring, four-ring, and five-ring PAH congeners accounting for about $6.0 \%, 50.7 \%$, and $43.3 \%$ of the total PAH contents, and the concentration of benzo[a] pyrene was $1,176 \pm 9 \mu \mathrm{g} \mathrm{kg}^{-1}$ dry soil. Considering the strong carcinogenic risk and food safety of agricultural soil, benzo[a]pyrene was selected as the main target contaminant of PAHs in the soil in this study.

\subsection{Organic fertilizer}

Organic fertilizer was purchased from an agricultural market in Nanjing, China. The physicochemical properties of the organic fertilizer were $\mathrm{pH} 3.5$ (1:2.5 organic fertilizer/water), moisture content $2.7 \%$, organic matter $221 \mathrm{~g} \mathrm{~kg}^{-1}$, total nitrogen $150 \mathrm{~g} \mathrm{~kg}^{-1}$, total phosphorus $3.83 \mathrm{~g} \mathrm{~kg}^{-1}$, and total potassium $19.2 \mathrm{gkg}^{-1}$. Benzo[a] pyrene was below detection level $\left(<0.1 \mathrm{\mu g} \mathrm{kg}^{-1}\right)$.

\subsection{Plants}

Alfalfa (M. sativa L.) seeds were purchased from Jiangsu Academy of Agricultural Science, China. Before sowing, the seeds were surface sterilized in a $10 \%(v / v)$ solution of hydrogen peroxide for $10 \mathrm{~min}$, rinsed with sterile distilled water, and germinated on moist filter paper for $24 \mathrm{~h}$.

\subsection{Experimental design and sample collection}

The pot experiment was carried out in a climate-controlled plant growth chamber. There were five treatments set up in a fully randomized layout: (1) sterilized soil as control (CK), (2) unplanted and unfertilized soil (U), (3) soil planted with alfalfa $(\mathrm{P}),(4)$ soil amended with $0.1 \%$ organic fertilizer (F), and (5) soil planted with alfalfa and amended with $0.1 \%$ organic fertilizer (PF). There were three replicates of each treatment.

Contaminated soil $(250 \mathrm{~g})$ was placed in each pot. Soil for the sterilized treatment was autoclaved at $121^{\circ} \mathrm{C}$ and $0.1 \mathrm{MPa}$ for $20 \mathrm{~min}$. Sterilized water was added to adjust the soil moisture content to $60 \%$ water holding capacity. As for the treatments of $\mathrm{F}$ and $\mathrm{PF}$, organic fertilizer as base fertilizer was applied into the soil and thoroughly mixed. After equilibration for $24 \mathrm{~h}$ in the climate-control chamber, ten germinated alfalfa seeds were sown $1 \mathrm{~cm}$ below the 
surface soil in each pot for treatments P and PF. Two weeks later, the weaker seedlings were removed to leave four seedlings in each pot. The plants were illuminated for a 14$\mathrm{h}$ photoperiod $\left(1.5 \times 10^{4} \mathrm{Lx}\right)$, and the temperature was maintained at $25^{\circ} \mathrm{C}$. The leachate from all pots was collected using the tray and returned to the soil. The plants were watered daily with sterilized water to maintain soil moisture during plant growth. Throughout the experiment, the pots were periodically repositioned to minimize edge effects.

The effects of soil sterilization on PAH dissipation were evaluated by collecting a soil sample of about $5.0 \mathrm{~g}$ after sterilization. After 60 days of cultivation, plant samples were carefully removed, washed with tap water to remove any attached soil particles, and oven-dried at $50^{\circ} \mathrm{C}$ to constant weight. Oven-dried plants were divided into shoots and roots, and ground for benzo[a]pyrene analysis. Soil in each pot was poured out on the stainless steel tray and thoroughly homogenized, and then sampled. Soil samples were freeze-dried, passed through a $0.3-\mathrm{mm}$ sieve, and stored at $4^{\circ} \mathrm{C}$ prior to benzo[a]pyrene analysis.

\subsection{Extraction and analysis of benzo[a]pyrene} in soil and plants

Benzo[a]pyrene in soil samples was extracted using Soxhlet extraction (Ni et al. 2008). In brief, $2.00 \mathrm{~g}$ of freeze-dried sample (equivalent to $1.94 \mathrm{~g}$ dry soil) and $2.00 \mathrm{~g}$ anhydrous sodium sulfate were mixed, wrapped with filter paper, and placed in a Soxhlet extractor. The extractor was then fitted to a $100-\mathrm{ml}$ round bottom flask containing $60 \mathrm{ml}$ dichloromethane, and the extraction was performed at $53^{\circ} \mathrm{C}$ for $24 \mathrm{~h}$ in a water bath. All the extracts in the round bottom flasks were dried by rotary evaporation. The residues were dissolved in $2.0 \mathrm{ml}$ of cyclohexane, and $0.5 \mathrm{ml}$ of the solute was transferred and purified with a silica gel column $(8 \times 220$-mm glass column filled with $1.0 \mathrm{~g}$ silica) and washed with a mixture of hexane and dichloromethane (1:1, $v / v)$. The first $1.0 \mathrm{ml}$ of eluate was discarded. The second $2.0 \mathrm{ml}$ aliquot of eluate was collected, dried by sparging with $\mathrm{N}_{2}$, and then redissolved in $1.0 \mathrm{ml}$ acetonitrile for high-performance liquid chromatography (HPLC) analysis.

Plant samples were extracted by an ultrasonication method (Song et al. 1995). Briefly, $1.00 \mathrm{~g}$ plant sample and $1.00 \mathrm{~g}$ anhydrous sodium sulfate were mixed and extracted with $20 \mathrm{ml}$ methanol at $30^{\circ} \mathrm{C}$ in an ultrasonicator $(600 \mathrm{~W})$ for $15 \mathrm{~min}$. The solvent was then decanted, collected, and replenished three times. The solvent fractions were combined, passed through a glass fiber filter, and dried by a rotary evaporator. The subsequent steps were the same as for the soil sample analysis as described above.

Analysis of benzo[a]pyrene was carried out according to the method of Qian et al. (2007). The analysis was conducted on a Shimadzu Class-VP HPLC system (Shimadzu, Kyoto, Japan) with a fluorescence detector (RF-10AXL). The reversed phase column (Varian Chrom Spher 5, Palo Alto, CA) was specialized for benzo[a]pyrene analysis. The detection limit for the benzo[a]pyrene was less than $0.1 \mu \mathrm{g} \mathrm{kg}^{-1}$.

\subsection{Statistical analysis}

Statistical analysis was carried out using the Origin 8.0 for Windows software package. Data were analyzed by twoway analysis of variance. Mean values were compared by least significant difference at the 0.05 level.

\section{Results}

\subsection{Soil benzo[a]pyrene dissipation}

After 60 days of cultivation, the residual concentrations of benzo[a]pyrene in the soil ranged from 245 to $1,072 \mu \mathrm{g} \mathrm{kg}^{-1}$ in the different treatments. The percent removal rates of soil benzo[a]pyrene in the different treatments are shown in Fig. 1. Only $8.8 \%$ of benzo[a] pyrene was dissipated in the abiotic sterile control treatment, while $66.7 \%$ was dissipated in unplanted soil. Planting alfalfa inhibited the dissipation of benzo[a]pyrene from soil by $8.9 \%$, while organic fertilizer increased benzo [a]pyrene removal by $11.6 \%$ when compared with the unplanted treatment. The percent removal rate of benzo[a] pyrene in organic fertilizer-amended planted soil was significantly lower than in the fertilized treatment but significantly higher than in the planted treatment. Analysis of variance showed no significant interaction between the effects of planting alfalfa and applying organic fertilizer on benzo[a]pyrene removal.

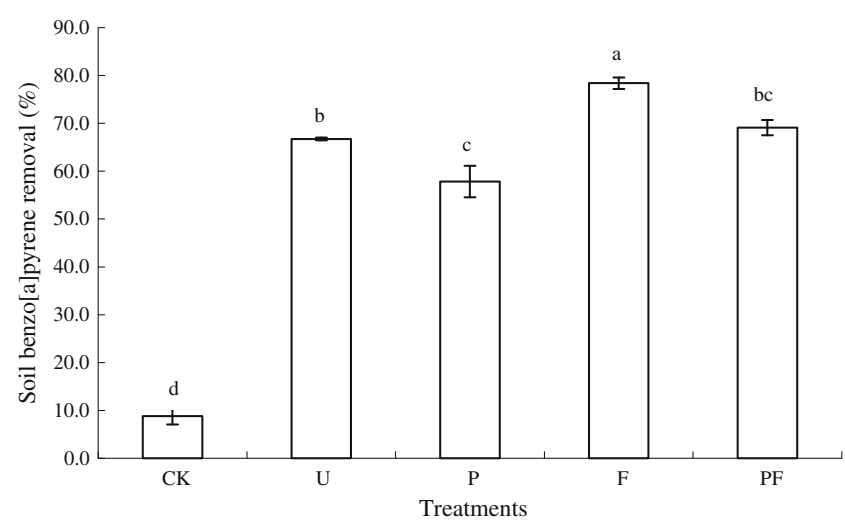

Fig. 1 Benzo[a]pyrene removal rate in different treatments after 60 days of alfalfa cultivation. $C K$ sterilized soil, $U$ unplanted and unfertilized soil, $P$ soil planted with alfalfa, $F$ fertilized soil, $P F$ soil planted with alfalfa and fertilized 
3.2 Plant biomass and benzo[a]pyrene accumulation in alfalfa roots and shoots

There were two planted treatments set up in this experiment as described above. Plant biomass and benzo[a]pyrene accumulated in alfalfa roots and shoots are presented in Table 1. Organic fertilizer significantly increased the shoot and total biomass of alfalfa but decreased the root biomass slightly. Higher concentrations of benzo[a]pyrene in alfalfa roots and shoots were observed in P than in PF. Organic fertilizer significantly decreased the benzo[a]pyrene concentrations in alfalfa roots and shoots. The amounts of benzo[a]pyrene that accumulated in alfalfa biomass were not significantly different between $\mathrm{P}$ and $\mathrm{PF}$ treatments. Compared with the amount of benzo[a]pyrene lost from the soil, benzo[a]pyrene extracted by plants could be ignored in both P and PF treatments.

\subsection{Soil mineral nitrogen concentrations and soil $\mathrm{pH}$}

The concentrations of soil mineral nitrogen (ammonium $\mathrm{N}$ and nitrate $\mathrm{N}$ ) at the end of the experiment are presented in Table 2. After 60 days of experiment, soil ammonium $\mathrm{N}$ concentrations across all treatments ranged from 1.93 to $8.43 \mathrm{mg} \mathrm{kg}^{-1}$ dry soil, and soil nitrate $\mathrm{N}$ concentrations ranged from 1.28 to $5.37 \mathrm{mg} \mathrm{kg}^{-1}$ dry soil. Compared with the initial concentrations of soil mineral $\mathrm{N}$, no significant changes were observed in $\mathrm{CK}$, while soil ammonium $\mathrm{N}$ decreased by $23.5 \%$ and nitrate $\mathrm{N}$ increased by $6.0 \%$ in the unplanted treatment. Planting alfalfa reduced the concentrations of ammonium $\mathrm{N}$ and nitrate $\mathrm{N}$. Organic fertilizer increased the soil mineral $\mathrm{N}$ concentration significantly.

Soil $\mathrm{pH}$ under the different treatments is shown in Table 2. Soil $\mathrm{pH}$ was influenced by planting alfalfa and applying organic fertilizer. Compared with the initial soil $\mathrm{pH}$, planting alfalfa increased the soil $\mathrm{pH}$ by 0.3 units and organic fertilizer amendment decreased the soil $\mathrm{pH}$ by 0.3 . Analysis of variance indicates that there were significant differences between the soil $\mathrm{pH}$ values under the different treatments.
3.4 Correlation between benzo[a]pyrene removal and soil physicochemical properties

Correlation analysis was used to evaluate the relationship between benzo[a]pyrene removal and soil properties. The results are given in Table 3. In general, significant positive correlations $(p<0.01)$ were observed between the benzo[a] pyrene removal and organic fertilizer, soil ammonium $\mathrm{N}$, nitrate $\mathrm{N}$, and total mineral $\mathrm{N}$. Soil $\mathrm{pH}$ was significantly and negatively correlated with the removal of benzo[a]pyrene $(p<0.01)$. However, no significant correlation $(p>0.01)$ was observed between planting of alfalfa and benzo[a]pyrene removal.

\section{Discussion}

In this study, the alfalfa cultivation had negative effects on benzo[a]pyrene removal, but up to $78 \%$ of soil benzo[a] pyrene was dissipated in the soil amended with $0.1 \%$ organic fertilizer $(\mathrm{F})$, a much larger amount than reported from similar studies ( $\mathrm{Li}$ et al. 2008; Wu et al. 2008). Moreover, we also found that sterilization completely inhibited benzo[a]pyrene removal. The $8.8 \%$ of benzo[a] pyrene dissipation in the abiotic sterile control treatment is due to non-biodegradation. As a semi-volatile compound, benzo[a]pyrene could evaporate partly from soil during the high-temperature sterilization process and be dissipated by photodegradation in the surface soil (Wild and Jones 1993). The removal was caused by biodegradation and enhanced by fertilizer application. This suggests that benzo[a]pyrenedegrading microorganisms may exist in the contaminated soil, and microbial degradation of benzo[a]pyrene by indigenous microorganisms was the main mechanism of benzo [a]pyrene removal from the soil. Biodegradation of benzo[a] pyrene in long-term contaminated soil by indigenous microorganisms has usually been considered to be a very long-term process (Bossert et al. 1984; Bossert and Bartha 1986; Coover and Sims 1987; Keck et al. 1989). The half-life of benzo[a] pyrene in soil ranges from 100 days to 14.6 years (Wild et al. 1991; Wilcock et al. 1996). It was therefore surprising

Table 1 Plant biomass and total benzo[a]pyrene uptake by alfalfa roots and shoots

\begin{tabular}{|c|c|c|c|c|c|}
\hline & \multicolumn{2}{|c|}{ Plant biomass $\left(\mathrm{g} \mathrm{pot}^{-1}\right)$} & \multicolumn{2}{|c|}{ Benzo[a]pyrene accumulated in plant (ng pot ${ }^{-1}$ ) } & \multirow{2}{*}{$\begin{array}{l}\text { Contribution of plant uptake to the soil } \\
\text { benzo[a]pyrene removal }(\%)\end{array}$} \\
\hline & Root & Shoot & Root & Shoot & \\
\hline $\mathrm{P}$ & $0.49 \mathrm{a}$ & $0.57 b$ & $1.06 \mathrm{a}$ & $1.23 b$ & 0.0016 \\
\hline PF & $0.40 \mathrm{a}$ & $1.01 \mathrm{a}$ & $0.64 b$ & $1.59 \mathrm{a}$ & 0.0013 \\
\hline
\end{tabular}

$P$ planted with alfalfa, $P F$ planted with alfalfa and amended with organic fertilizer. Within columns, mean values with different letters are significantly different $(p<0.05)$ 
Table 2 Soil ammonium $\mathrm{N}$ and nitrite $\mathrm{N}$ concentrations and soil $\mathrm{pH}$ under the different treatments

\begin{tabular}{llll}
\hline Treatment & $\begin{array}{l}\text { Soil ammonium N } \\
\left(\mathrm{mg} \mathrm{kg}^{-1} \text { dry soil }\right)\end{array}$ & $\begin{array}{l}\text { Soil nitrate N } \\
\left(\mathrm{mg} \mathrm{kg}^{-1} \text { dry soil }\right)\end{array}$ & Soil pH \\
\hline CK & $5.25 \pm 0.11 \mathrm{~b}$ & $3.79 \pm 0.60 \mathrm{~b}$ & $4.77 \pm 0.02 \mathrm{a}$ \\
$\mathrm{U}$ & $3.84 \pm 0.18 \mathrm{c}$ & $3.35 \pm 0.27 \mathrm{~b}$ & $4.61 \pm 0.02 \mathrm{~b}$ \\
$\mathrm{P}$ & $1.93 \pm 0.02 \mathrm{~d}$ & $1.28 \pm 0.10 \mathrm{c}$ & $4.76 \pm 0.01 \mathrm{a}$ \\
$\mathrm{F}$ & $8.43 \pm 0.50 \mathrm{a}$ & $5.37 \pm 0.20 \mathrm{a}$ & $4.24 \pm 0.03 \mathrm{~d}$ \\
$\mathrm{PF}$ & $5.73 \pm 0.50 \mathrm{~b}$ & $3.56 \pm 0.27 \mathrm{~b}$ & $4.32 \pm 0.01 \mathrm{c}$ \\
\hline
\end{tabular}

$C K$ sterilized soil, $U$ unplanted soil, $P$ soil planted with alfalfa, $F$ soil with organic fertilizer, $P F$ soil planted with alfalfa and amended with organic fertilizer. Within columns, mean values with different letters are significantly different $(p<0.05)$

that about $78 \%$ of soil benzo[a]pyrene was dissipated during the 60 days of cultivation in the present study, and the organisms degrading benzo[a]pyrene in this soil deserve further study. Furthermore, the soil properties and environmental conditions in our study appeared to be suitable for biodegradation of benzo[a]pyrene. A relatively low soil $\mathrm{pH}$, a constant temperature, and a favorable moisture content may be conducive to biodegradation of benzo[a]pyrene.

Alfalfa was considered to be a promising candidate for phytoremediation of PAH-contaminated soil (Muratova et al. 2003; Teng et al. 2011). However, the results of our study indicate that planting alfalfa inhibited benzo[a]pyrene removal from the long-term contaminated soil. According to the correlation analysis, the residual mineral $\mathrm{N}$ concentration was positively related to the benzo[a]pyrene removal rate from soil. Alfalfa growth removes much mineral $\mathrm{N}$ from the soil and resulted in a significant decrease of the total mineral $\mathrm{N}$ by $60.7 \%$ of the initial soil concentration, suggesting that competition between plants and microorganisms for nitrogen may have impeded benzo[a]pyrene removal from the rhizosphere of alfalfa. Smith et al. (2008)

Table 3 Correlation between benzo[a]pyrene removal rate and soil physicochemical properties

\begin{tabular}{lcc}
\hline & \multicolumn{2}{l}{ Removal rate of soil benzo[a]pyrene } \\
\cline { 2 - 3 } & Correlation coefficient & $P$ value \\
\hline Planting alfalfa & -0.607 & $3.61 \times 10^{-2}$ \\
Organic fertilization & 0.766 & $3.69 \times 10^{-3}$ a \\
Soil ammonium N & 0.955 & $1.38 \times 10^{-6}$ a \\
Soil nitrate N & 0.964 & $4.55 \times 10^{-7}$ a \\
Total mineral N & 0.969 & $2.24 \times 10^{-7}$ a \\
Soil pH & -0.896 & $8.00 \times 10^{-5}$ a \\
\hline
\end{tabular}

Correlation is significant at the 0.01 level (two-tailed). For planting alfalfa and organic fertilization parameters, planted and fertilized soil were defined as 1 and unplanted and non-fertilized soil were defined as -1 reported that total $\mathrm{N}$ removal by plants was negatively correlated with percent loss of phenanthrene $\left(r^{2}, 0.73\right)$, chrysene $\left(r^{2}, 0.80\right)$, fluoranthene $\left(r^{2}, 0.56\right)$, and pyrene $\left(r^{2}\right.$, 0.55 ) in a 3-year field study. Hutchinson et al. (2001) found that when fertilizer was applied by weekly irrigation instead of daily irrigation, the vegetation did not significantly impact PAH dissipation, leading to the conclusion that roots and microbial populations quickly depleted the available $\mathrm{N}$ from the irrigation water and used it for cellular functions of growth rather than breakdown of PAH contaminants in the soil. There was a significant negative relationship between total petroleum hydrocarbon (TPH, C11 to $\mathrm{C} 40$ ) degradation and initial concentration of ammonium $\mathrm{N}$ in aged composts. Lack of $\mathrm{N}$ fertilizer impacted TPH in composts, and application of ammonium-based fertilizer was a useful measure to enhance phytoremediation when ammonium availability was low (Choi and Chang 2009). Nitrogen is also the major nutrient in bioremediation projects in order to adjust the carbon-to-nitrogen ratio of the soil. Nitrogen is primarily used for cellular growth $\left(\mathrm{NH}_{4}{ }^{+}\right.$or $\left.\mathrm{NO}_{3}{ }^{-}\right)$and as an alternative electron acceptor $\left(\mathrm{NO}_{3}{ }^{-}\right)$. The PAHs dissipation effect at a $\mathrm{C} / \mathrm{N}$ ratio of 10:1 was significantly higher than at a $\mathrm{C} / \mathrm{N}$ of either $25: 1$ or $40: 1$ (Teng et al. 2010). Joner et al. (2002) also found that N, P, and root exudates were necessary for phytoremediation and suggested intensive fertilization with slow release fertilizers to ensure the replenished mineral nutrients for both plant and microbial populations. One of the main mechanisms for phytoremediation of organic contaminants with alfalfa is rhizodegradation, which is an important chemical-biological process by alfalfa root exudates stimulating indigenous microbial communities to utilize organic contaminants in the rhizosphere soil. During the rhizodegradation, plant growth and microbial activities all need nutrient, especially nitrogen source may be a limited factor. A negative impact of mycorrhizal plants on PAH dissipation (Joner et al. 2006) was speculated to be the result of mycorrhiza scavenging $\mathrm{N}$ and depleting the soil of critical nutrients for microbial degradation of the contaminants. Plants and microbes can compete for nutrients in the soils and sediments and may have negatively affected the microbial activity (Kaye and Hart 1997; Hodge et al. 2000; Joner et al. 2002), resulting in less efficient phytoremediation of PAHs. Taken together, our results lead us to conclude that in order for phytoremediation to be effective, the plants must be optimally fertilized to support plant growth while also maximizing the activity of the populations of PAHdegrading microorganisms.

Soil $\mathrm{pH}$ is an important factor which affects benzo[a] pyrene removal from contaminated soils. Lower soil $\mathrm{pH}$ is beneficial for benzo[a]pyrene degradation. The soil $\mathrm{pH}$ was influenced by planting alfalfa and applying organic fertilizer. Several previous studies suggested that planting alfalfa 
increased soil pH slightly (Moreira and Fageria 2010). However, other studies have indicated that planting alfalfa can decrease soil pH (Chen et al. 2001; Yang et al. 2009) or cannot give obvious change to soil $\mathrm{pH}$ (Zhang and $\mathrm{Hu}$ 2004). How planting alfalfa affects soil pH may be related with soil types. The influence of organic fertilizer on soil $\mathrm{pH}$ will depend on the properties of both soil and fertilizer. The $\mathrm{pH}$ of organic fertilizer used in this study was 3.5, which was significantly lower than the initial soil $\mathrm{pH}$. Thus, the soil $\mathrm{pH}$ was acidified by application of the fertilizer.

\section{Conclusions}

Under our experimental conditions, short-term planting of alfalfa inhibited benzo[a]pyrene dissipation from the aged contaminated agricultural soil and organic fertilizer application led to a significant increase in benzo[a]pyrene removal from the soil. Furthermore, soil mineral $\mathrm{N}$ concentrations and soil $\mathrm{pH}$ were significantly correlated with benzo [a]pyrene removal. A better understanding of the mechanism of benzo[a]pyrene dissipation will depend on the identification and characterization of native microbial degraders of the $\mathrm{PAH}$ in the soil.

Acknowledgments This work was supported by grants from the Natural Science Foundation of Jiangsu Province (Project BK2009016), the Knowledge Innovation Program of the Chinese Academy of Sciences (Project KSCX2-YW-G-071), and the National High Technology Research and Development Program of China (863 Program) Project 2007AA061101).

Open Access This article is distributed under the terms of the Creative Commons Attribution Noncommercial License which permits any noncommercial use, distribution, and reproduction in any medium, provided the original author(s) and source are credited.

\section{References}

Binet P, Portal JM, Leyval C (2000) Dissipation of 3-6-ring polycyclic aromatic hydrocarbons in the rhizosphere of ryegrass. Soil Biol Biochem 32:2011-2017

Bossert ID, Kachel MW, Bartha R (1984) Fate of hydrocarbons during oily sludge disposal in soil. Appl Environ Microbiol 47:763-767

Bossert ID, Bartha R (1986) Structure-biodegradability relationships of polycyclic aromatic hydrocarbons in soil. B Environ Contam Tox 37:490-495

CCME (2004) Canadian soil quality guidelines for the protection of environmental and human health: summary tables. Updated. CCME, Winnipeg

Chekol T, Vough LR, Chaney RL (2004) Phytoremediation of polychlorinated biphenyl-contaminated soils: the rhizosphere effect. Environ Int 30:799-804

Chen W, McCaughey WP, Grant CA, Bailey LD (2001) Pasture type and fertilization effects on soil chemical properties and nutrient redistribution. Can J Soil Sci 81:395-404
Cheng KY, Lai KM, Wong JWC (2008) Effects of pig manure compost and nonionic-surfactant Tween 80 on phenanthrene and pyrene removal from soil vegetated with Agropyron elongatum. Chemosphere 73:791-797

Choi WJ, Chang SX (2009) Technical note: nitrogen fertilization effects on the degradation of aged diesel oil in composted drilling wastes. Int J Phytoremediation 11:441-450

Cofield N, Schwab AP, Banks MK (2007) Phytoremediation of polycyclic aromatic hydrocarbons in soil: part 1. Dissipation of target contaminants. Int J Phytoremediation 9:355-370

Coover MP, Sims RC (1987) The effect of temperature on polycyclic aromatic hydrocarbon persistence in an unacclimated agricultural soil. Hazard Waste Hazard 4:69-82

Fan SX, Li PJ, Gong ZQ, Ren WX, He N (2008) Promotion of pyrene degradation in rhizosphere of alfalfa (Medicago sativa L.). Chemosphere 71:1593-1598

Flowers L, Rieth SH, Cogliano VJ, Foureman GL, Hertzberg R, Hofmann EL, Murphy DL, Nesnow S, Schoeny RS (2002) Health assessment of polycyclic aromatic hydrocarbon mixtures: current practices and future directions. Polycycl Aromat Comp 22:811-821

Hodge A, Robinson D, Fitter A (2000) Are microorganisms more effective than plants at competing for nitrogen? Trends Plant Sci 5:304-308

Hutchinson SL, Schwab AP, Banks MK (2001) Phytoremediation of aged petroleum sludge: effect of irrigation techniques and scheduling. J Environ Qual 30:1516-1522

Johnsen AR, Karlson U (2007) Diffuse PAH contamination of surface soils: environmental occurrence, bioavailability, and microbial degradation. Appl Microbiol Biotechnol 76:533-543

Joner EJ, Corgie SC, Amellal N, Leyval C (2002) Nutritional constraints to degradation of polycyclic aromatic hydrocarbons in a simulated rhizosphere. Soil Biol Biochem 34:859-864

Joner EJ, Leyval C, Colpaert JV (2006) Ectomycorrhizas impede phytoremediation of polycyclic aromatic hydrocarbons (PAHs) both within and beyond the rhizosphere. Environ Pollut 142:3438

Kaye JP, Hart SC (1997) Competition for nitrogen between plants and soil microorganisms. Trends Ecol Evol 12:139-143

Keck J, Sims RC, Coover MP (1989) Evidence for cooxidation of polynuclear aromatic hydrocarbons in soil. Water Res 23:14671476

Li XJ, Li PJ, Lin X, Zhang CG, Li Q, Gong ZQ (2008) Biodegradation of aged polycyclic aromatic hydrocarbons (PAHs) by microbial consortia in soil and slurry phases. J Hazard Mater 150:21-26

Liste HH, Alexander M (2000) Plant-promoted pyrene degradation in soil. Chemosphere 40:7-10

Lu RK (1999) Analytical methods of soil and agricultural chemistry. China Agricultural Science and Technology Press, Beijing

Moreira A, Fageria NK (2010) Liming influence on soil chemical properties, nutritional status and yield of alfalfa. Rev Bras Ciênc Solo 34:1231-1239

Muratova A, Hubner Th, Tischer S, Turkovskaya O, Möder M, Kuschk P (2003) Plant-rhizosphere-microflora association during phytoremediation of PAH-contaminated soil. Int J Phytoremediation 5:137-151

Ni JZ, Luo YM, Wei R, Li XH (2008) Distribution patterns of polycyclic aromatic hydrocarbons among different organic carbon fractions of polluted agricultural soils. Geoderma $146: 277-282$

Patrolecco L, Ademollo N, Capri S, Pagnotta R, Polesello S (2010) Occurrence of priority hazardous PAHs in water, suspended particulate matter, sediment and common eels (Anguilla anguilla) 
in the urban stretch of the River Tiber (Italy). Chemosphere $81: 1386-1392$

Peng RH, Xiong AS, Xue Y, Fu XY, Gao F, Zhao W, Tian YS, Yao QH (2008) Microbial biodegradation of polyaromatic hydrocarbons. FEMS Microbiol Rev 32:927-955

Qian W, Ni JZ, Luo YM, Li XH, Zou DX (2007) Determination of polycyclic aromatic hydrocarbons in soil by high performance liquid chromatography with fluorescence detection. Chin J Chromatogr 25:221-225

Samanta SK, Singh OV, Jain RK (2002) Polycyclic aromatic hydrocarbons: environmental pollution and bioremediation. Trends Biotechnol 20:243-248

Silva IS, dos Santos E, de Menezes CR, Faria AF, Franciscon E, Grossman M, Durrant LR (2009) Bioremediation of polyaromatic hydrocarbon contaminated soil by native soil microbiota and bioaugmentation with isolated microbial consortia. Bioresour Technol 100:4669-4675

Smith KE, Schwab AP, Banks MK (2008) Dissipation of PAHs in saturated, dredged sediments: a field trial. Chemosphere 72:1614-1619

Song YF, Ou ZQ, Sun TH (1995) Analytical method of polycyclic aromatic hydrocarbons (PAHs) in soil and plant samples. Chin J Appl Ecol 6:92-96

Teng Y, Luo YM, Ping LF, Zou DX, Li ZG, Christie P (2010) Effects of soil amendment with different carbon sources and other factors on the bioremediation of an aged PAH-contaminated soil. Biodegradation 21:167-178

Teng Y, Shen YY, Luo YM, Sun XH, Sun MM, Fu DQ, Li ZG, Christie P (2011) Influence of Rhizobium meliloti on phytoremediation of polycyclic aromatic hydrocarbons by alfalfa in an aged contaminated soil. J Hazard Mater 186:1271-1276

Wei SQ, Pan SW (2010) Phytoremediation for soils contaminated by phenanthrene and pyrene with multiple plant species. J Soils Sediments 10:886-894

Wetzel SC, Banks MK, Schwab AP (1997) Rhizosphere effects on the degradation of pyrene and anthracene in soil. In: Kruger EL,
Anderson TA, Coats JR (eds) Phytoremediation of soil and water contaminants. American Chemical Society, Washington, DC, pp $254-262$

Wilcke W (2007) Global patterns of polycyclic aromatic hydrocarbons (PAHs) in soil. Geoderma 141:157-166

Wilcock RJ, Corban GA, Northcott GL, Wilkins AL, Langdon AG (1996) Persistence of polycyclic aromatic compounds of different molecular size and water solubility in surfcial sediment of an intertidal sandflat. Environ Toxicol Chem 15:670-676

Wild SR, Jones KC (1993) Biological and abiotic losses of polynuclear aromatic hydrocarbons (PAHs) from soils freshly amended with sewage sludge. Environ Toxicol Chem 12:5-12

Wild SR, Jones KC (1995) Polynuclear aromatic hydrocarbons in the United Kingdom environment: a preliminary source in inventory and budget. Environ Pollut 88:91-108

Wild SR, Obbard JP, Munn CI, Berrow ML, Jones KC (1991) The long-term persistence of polynuclear aromatic hydrocarbons (PAHs) in an agricultural soil amended with metal-contaminated sewage sludges. Sci Total Environ 10:235-253

Wolz J, Schulze T, Lubcke-von VU, Fleig M, Reifferscheid G, Brack W, Kuhlers D, Braunbeck T, Hollert H (2011) Investigation on soil contamination at recently inundated and uninundated sites. $\mathrm{J}$ Soils Sediments 11:82-92

Wu YC, Luo YM, Zou DX, Ni JZ, Liu WX, Teng Y, Li ZG (2008) Bioremediation of polycyclic aromatic hydrocarbons contaminated soil with Monilinia sp.: degradation and microbial community analysis. Biodegradation 19:247-257

Yang HS, Zhang QG, Tai JC, Ge XL, Wang NN (2009) Effects of growth years on soil $\mathrm{pH}$ and phosphatase activities in alfalfa fields. Chin J Grassland 31:32-35

Zhang XQ, Hu MG (2004) The effect of alfalfa on physical and chemical properties of saline soil. Pratacult Sci 21:31-34

Zhang J, Yin R, Lin XG, Liu WW, Chen RR, Li XZ (2010) Interactive effect of biosurfactant and microorganism to enhance phytoremediation for removal of aged polycyclic aromatic hydrocarbons from contaminated soils. J Health Sci 56:257-266 